The University of Southern Mississippi

The Aquila Digital Community

Faculty Publications

$5-1-2011$

\title{
Dynamic Topography of the Bering Sea
}

\author{
Gleb Panteleev \\ University of Alaska, gleb@iarc.uaf.edu \\ Max Yaremchuk \\ Stennis Space Center \\ Phyllis J. Stabeno \\ NOAA Pacific Marine Environmental Laboratory, phyllis.stabeno@noaa.gov \\ Vladimir Luchin \\ Russian Academy of Sciences \\ Dmitri A. Nechaev \\ University of Southern Mississippi, dmitri.nechaev@usm.edu
}

See next page for additional authors

Follow this and additional works at: https://aquila.usm.edu/fac_pubs

\section{Recommended Citation}

Panteleev, G., Yaremchuk, M., Stabeno, P. J., Luchin, V., Nechaev, D. A., Kikuchi, T. (2011). Dynamic Topography of the Bering Sea. Journal of Geophysical Research-Oceans, 116.

Available at: https://aquila.usm.edu/fac_pubs/527

This Article is brought to you for free and open access by The Aquila Digital Community. It has been accepted for inclusion in Faculty Publications by an authorized administrator of The Aquila Digital Community. For more information, please contact Joshua.Cromwell@usm.edu. 


\section{Authors}

Gleb Panteleev, Max Yaremchuk, Phyllis J. Stabeno, Vladimir Luchin, Dmitri A. Nechaev, and Takashi Kikuchi 


\title{
Dynamic topography of the Bering Sea
}

\author{
Gleb Panteleev, ${ }^{1}$ Max Yaremchuk, ${ }^{2}$ Phyllis J. Stabeno, ${ }^{3}$ Vladimir Luchin, ${ }^{4}$ \\ Dmitri A. Nechaev, ${ }^{5}$ and Takashi Kikuchi ${ }^{6}$ \\ Received 30 April 2010; revised 1 February 2011; accepted 15 February 2011; published 25 May 2011.
}

[1] A new mean dynamic topography (MDT) for the Bering Sea is presented. The product is obtained by combining historical oceanographic and atmospheric observations with high-resolution model dynamics in the framework of a variational technique. Eighty percent of the ocean data underlying the MDT were obtained during the last 25 years and include hydrographic profiles, surface drifter trajectories, and in situ velocity observations that were combined with National Centers for Environmental Prediction (NCEP)/National Center for Atmospheric Research (NCAR) atmospheric climatology. The new MDT quantifies surface geostrophic circulation in the Bering Sea with a formal accuracy of $2-4 \mathrm{~cm} / \mathrm{s}$. The corresponding sea surface height (SSH) errors are estimated by inverting the Hessian matrix in the subspace spanned by the leading modes of SSH variability observed from satellites. Comparison with similar products based on in situ observations, satellite gravity, and altimetry shows that the new MDT is in better agreement with independent velocity observations by Argo drifters and moorings. Assimilation of the satellite altimetry data referenced to the new MDT allows better reconstruction of regional circulations in the Bering Sea. Comparisons also indicate that MDT estimates derived from the latest Gravity Recovery and Climate Experiment geoid model have more in common with the presented sea surface topography than with the MDTs based on earlier versions of the geoid. The presented MDT will increase the accuracy of calculations of the satellite altimeter absolute heights and geostrophic surface currents and may also contribute to improving the precision in estimating the geoid in the Bering Sea.

Citation: Panteleev, G., M. Yaremchuk, P. J. Stabeno, V. Luchin, D. A. Nechaev, and T. Kikuchi (2011), Dynamic topography of the Bering Sea, J. Geophys. Res., 116, C05017, doi:10.1029/2010JC006354.

\section{Introduction}

[2] The density and diversity of oceanographic observations in the Bering Sea increased significantly during the last decades. The observations comprise conventional temperature/salinity data, a large number of high-quality velocity time series from moorings [e.g., Woodgate et al., 2005], and surface [Niiler, 2001] and subsurface (Argo) profiling floats [Wilson, 2000]. The surface drifter program has allowed a quantitative determination of the basic features of the Bering Sea surface circulation [Stabeno et al., 1999].

[3] Since 1992, satellite radar altimetry has become a conventional tool for remote monitoring of global sea level

\footnotetext{
${ }^{1}$ International Arctic Research Center, University of Alaska, Fairbanks, Alaska, USA.

${ }^{2}$ Naval Research Laboratory, Stennis Space Center, Mississippi, USA.

${ }^{3}$ NOAA Pacific Marine Environmental Laboratory, Seattle, Washington, USA.

${ }^{4}$ Far Eastern Branch, Russian Academy of Science, Vladivostok, Russia.

${ }^{5}$ Department of Marine Science, University of Southern Mississippi, Stennis Space Center, Mississippi, USA.

${ }^{6}$ Research Institute for Global Change, Japan Agency for Marine-Earth Science and Technology, Yokosuka, Japan.

Copyright 2011 by the American Geophysical Union. 0148-0227/11/2010JC006354
}

variations. Development of instrumental technology and processing techniques and utilization of multisatellite data sets have reduced satellite altimetry product errors to the point that these products can be used to detect sea surface height ( $\mathrm{SSH})$ variations associated with ocean currents and to resolve upper ocean mesoscale eddies. Combined together, data from the TOPEX/Poseidon, Jason-1, Jason-2, Earth Resources Satellite (ERS)-1 and -2, Envisat, and Geosat Follow-On (GFO) missions span the time period from October 1992 to present.

[4] In contrast to the increasing accuracy of detecting SSH variations, the difference between a time-averaged sea surface and geoid (mean dynamic topography (MDT)) can be retrieved from altimetry with much lower precision. The problem is due to the large uncertainties in the geoid models. Although the recent Gravity Recovery and Climate Experiment (GRACE) mission (http://www.csr.utexas.edu/grace/) significantly improved the geoid, it remains too coarse to be directly used for circulation studies in the marginal seas. The situation may improve with the recent launch of the Gravity field and steady state Ocean Circulation Explorer (GOCE) mission.

[5] In the meantime, a number of research groups have developed methods to combine various data with altimetry to obtain more accurate estimates of the global MDT [Niiler et al., 2003; Rio et al., 2005; Maximenko et al., 2009]. For 
various reasons, all these products have substantial deficiencies in the Bering Sea. The common cause is that statistical assumptions underlying these global products were not fine-tuned locally, but SSH statistics strongly depends on local dynamics, which is affected in turn by stratification and smaller-scale topographic features.

[6] Alternative approaches include MDT estimation as an ensemble average of regional model solutions [e.g., Bingham and Haines, 2006], or as a diagnostic solution of the ocean model forced by seasonal climatology [Foreman et al., 2008]. Both methods take into account dynamical information but have certain limitations in assessing the MDT errors due to limited ensemble size and uncertainties in model forcing.

[7] The four-dimensional variational (4DVar) data assimilation technique computes MDT as a component of the mean climatological circulation; this method satisfies model equations on the one hand, while on the other hand it provides the least discrepancy with observations. The 4DVar technique has proved to be a useful and efficient tool in numerous ocean circulation studies [e.g., Wunsch, 1996; Awaji et al., 2003; Panteleev et al., 2006a]. A disadvantage of this approach is its computational cost which prevents production of global 4DVar analyses [Stammer et al., 2002; Menemelis et al., 2009] at resolutions better than $0.25^{\circ}$.

[8] On the basin scale, variational inversions at high latitudes are known in literature for almost two decades. The early efforts were limited to 3Dvar steady state problems at modest resolutions with simplified dynamics [Brasseur, 1991; Grotov et al., 1998; Yaremchuk, 2001]. More recent four-dimensional variational inversions were made at $0.1^{\circ}$ $0.2^{\circ}$ resolution with primitive equation constraints [e.g., Panteleev et al., 2006a, 2010; Powell et al., 2008; Hoteit et al., 2010]. Panteleev et al. [2006b] reconstructed the mean summer climatological circulation in the northern Bering Sea and found a reasonably good agreement with the Argo drifters velocities at $1000 \mathrm{~m}$ [Yoshinari et al., 2006].

[9] In the present study we employ a 4DVar inversion of a primitive equation model to reconstruct the MDT in the Bering Sea. The model has a horizontal resolution of $18 \mathrm{~km}$, which is slightly larger than the average baroclinic radius of deformation (15 km [e.g., Chelton et al., 1998]). This choice both insures stability of the tangent linear and adjoint models and allows the most important topographic features to be resolved, including the passes through the Aleutian Arc.

[10] Special attention is paid to a posteriori error analysis of the optimal SSH field, which is accomplished by inverting the Hessian matrix of the assimilation problem. This inversion is performed in the low-dimensional subspace spanned by the leading modes of the SSH variability observed by satellites. To validate the product, we also estimate its properties in selected regions of the Bering Sea against the available data and compare it with the global highresolution MDTs derived recently from in situ observations, altimeter data, and geoid models. These comparisons indicate, in particular, that the latest GRACE geoid model provides an improved MDT estimate in the open sea regions.

[11] The paper is organized as follows. In section 2 we describe the data sets used and the techniques of data assimilation and error analysis. The optimized MDT and results of climatological reconstruction of the Bering Sea circulation are presented in section 3 . Also in section 3 local circulations in the Amukta Pass, Eastern Bering Sea shelf, the Bering Slope, and the Kamchatka and Alaska currents are reconstructed using four different MDTs (including the present one) and the respective flow fields are compared against independent drifter and mooring data. In section 4 the results are summarized.

\section{Methodology}

\subsection{Data}

[12] The following data were utilized in the reconstruction of the MDT:

[13] 1 . The 81,911 temperature/salinity profiles that were collected in the Chukchi and Bering seas between 1932 and 2004 (Figure 1). This database includes bottle data, mechanical bathythermograph data, high-resolution conductivitytemperature-depth (CTD) profiles, expendable bathythermograph and PALACE Argo float data. More than 50\% of these data were obtained during the period 1980-2004. The major part of the data was obtained from the Russian archives in RIHMI-WDC (http://nodc.meteo.ru/nodc/), JODC (http:// www.jodc.go.jp/), University of Alaska (http://www.ims.uaf. edu), databases of the World Ocean Data Center [Conkright et al., 2002], and the Argo Global Data Assembly Centre (http://www.coriolis.eu.org/). Preprocessing of the data included quality control, which consisted of averaging the profiles in time and over the $28 \times 28 \mathrm{~km}$ bins and computing the standard deviations $\sigma_{T}, \sigma_{S}$ from statistics within the bins. Spatial distributions of the resulting mean temperature $T$ (Figure 2a), salinity $S, \sigma_{T}$, and $\sigma_{S}$ were used in the reconstruction of the mean Bering Sea state. The values of $\sigma_{T}$ and $\sigma_{S}$ varied within the ranges $1.5^{\circ} \mathrm{C}-4^{\circ} \mathrm{C}$ (Figure $2 \mathrm{~b}$ ) and $0.1-$ $2.0 \mathrm{ppt}$ near the surface and decreased to $0.1^{\circ} \mathrm{C}$ and $0.03 \mathrm{ppt}$, respectively, in the deeper layers. The total number of hydrographic data points used in the analysis was 184,109 for temperature and 178,529 for salinity.

[14] 2. About 500 satellite-tracked drifter trajectories from the Fisheries Oceanography Coordinated Investigations (FOCI) database (http://www.pmel.noaa.gov/foci) and 84 drifter trajectories from the Global Drifter Program (GDP) database (http://www.aoml.noaa.gov/phod/dac/) observed during 1984-2004. The FOCI surface drifters were drogued at $40 \mathrm{~m}$ and GDP drifters had drogues at $15 \mathrm{~m}$. Preliminary analysis of these data included: (1) temporal low-pass filtering of the trajectories with 7 day cutoff period, and (2) calculating the mean gridded velocities and the corresponding error variances through spatial averaging of the drifter velocities within the $30 \mathrm{~km}$ circles. The average error variance ranged from 5 to $20 \mathrm{~cm} / \mathrm{s}$. Only 5515 gridded velocities obtained from averaging of at least three different surface drifters were assimilated (Figure 3a). Most $(82 \%)$ of these velocity data were obtained from FOCI drifters driven by currents below the Ekman layer.

[15] 3. Velocity time series from 57 moorings. Most of these data come from the Alaska Ocean Observing System (AOOS) database (http://www.aoos.org) encompassing the period of 1970-2005. Many of the AOOS velocity time series are only 2-4 months long and cannot be a source for reliable estimates of climatological currents. To avoid contamination of the optimal solution by a presumably strong "subseasonal" signal, error variances of the AOOS monthly mean data were taken as the largest of the following three 


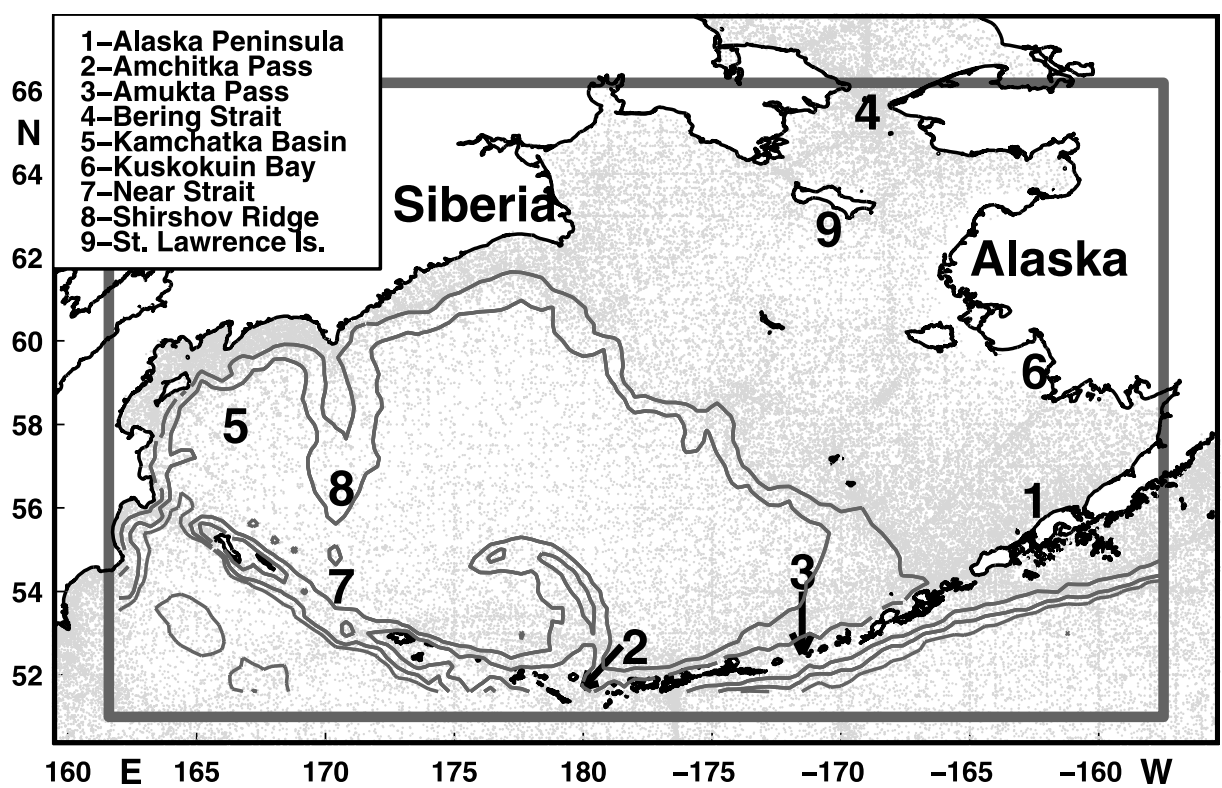

Figure 1. Coverage of the model domain (solid rectangle) by hydrographic stations. Bathymetry contours of 1000 and $3000 \mathrm{~m}$ are shown.

values: $5 \mathrm{~cm} / \mathrm{s}$ (an estimate of seasonal variability of the vector-averaged velocity amplitude), or $20 \%$ of the monthly mean velocity amplitude, or the RMS variation of the original velocity time series. The total number of assimilated velocity observations from this source was 114 (Figure 3b).

[16] 4. The Bering Strait transport estimate of $0.9 \pm 0.2 \mathrm{~Sv}$ was taken from Woodgate et al. [2005]. The estimates of this transport are based on the data collected since 1990-2004.

[17] 5. The wind stress and surface heat/salt fluxes were taken from the National Centers for Environmental Prediction (NCEP)/National Center for Atmospheric Research (NCAR) climatologies averaged over the period of 19482006 (http://www.esrl.noaa.gov/psd/data/gridded/data.ncep. reanalysis.derived.html). Since these products may contain substantial errors in the Bering Sea [Ladd and Bond, 2002], we used wind stress and surface flux data with relatively high error variances equal to $40 \%$ of their spatiotemporal RMS variation over the basin. The total number of surface flux observations was 34,888 .

[18] All the above data sets differ in temporal coverage; in addition, their temporal distribution is uneven. We estimated that $80 \%$ of all the considered oceanic data were acquired between 1981 and 2006. Most importantly, this period encompasses all the surface drifter observations which have a major impact on the reconstructed MDT, and coincides with the time span of massive satellite observations of the ocean surface. For these reasons we assume that the reconstructed MDT represents best the 20 year period of 1986-2006.

\subsection{Analysis Technique}

[19] The mean climatological state of the Bering Sea was found as a data-optimized solution of the primitive equation model already used by Panteleev et al. [2006b] for retrieving the mean summer circulation in the northern part of the basin and in the Kara Sea [Panteleev et al., 2007]. The numerical model is a modification of the $\mathrm{C}$ grid, $z$ coordinate Ocean General Circulation Model (OGCM) designed by
Madec et al. [1999] (see Nechaev et al. [2005] for details). The model was configured in the domain shown in Figure 1 with meridional and zonal resolutions of $0.16^{\circ}$ and $0.3^{\circ}$, respectively. The corresponding grid step $(18 \mathrm{~km})$ is larger than the Rossby deformation radius to suppress mesoscale eddies, but it is fine enough to resolve the major topographic and circulation features, including the Near Strait, the Amchitka and Amukta passes, and the Kamchatka Current. Vertically, the grid had 34 levels with spacing ranging from $5 \mathrm{~m}$ near the surface to $500 \mathrm{~m}$ in the deep layers.

[20] The model resolution $(18 \mathrm{~km})$ was chosen to be somewhat larger than typical resolution of the altimetry observations $(10 \mathrm{~km})$, which barely resolve the local deformation radius $(15 \mathrm{~km})$ and mesoscale eddy dynamics. Apart from the immense computational cost of the eddy-resolving 4DVar assimilation [e.g., Hoteit et al., 2010; Mazloff et al., 2010], this choice of a coarser grid was made to avoid regularization of the adjoint model through the artificial increase of the horizontal diffusion. Effectively, such an approach performs optimization in the subspace of smooth model solutions, consistent with the large diffusion of the adjoint model, and may not converge on the "true" optimal solution [e.g., Yaremchuk et al., 2009].

[21] A 4DVar data assimilation algorithm was configured to find a quasi-stationary solution to model equations that optimally fits the oceanic and atmospherical observations described above. Following the approach of Tziperman and Thacker [1989], in the first guess we specified initial and boundary conditions and integrated the model for a period of several weeks with steady climatological momentum and heat/salt fluxes at the surface. Both surface forcing and initial/boundary conditions were imposed as weak constraints, i.e., they were iteratively optimized in the course of assimilation. Technically, the optimization procedure can be viewed as a dynamically constrained minimization of the cost function $J$ which measures the distance between the model solution and the data. The minimization is performed 

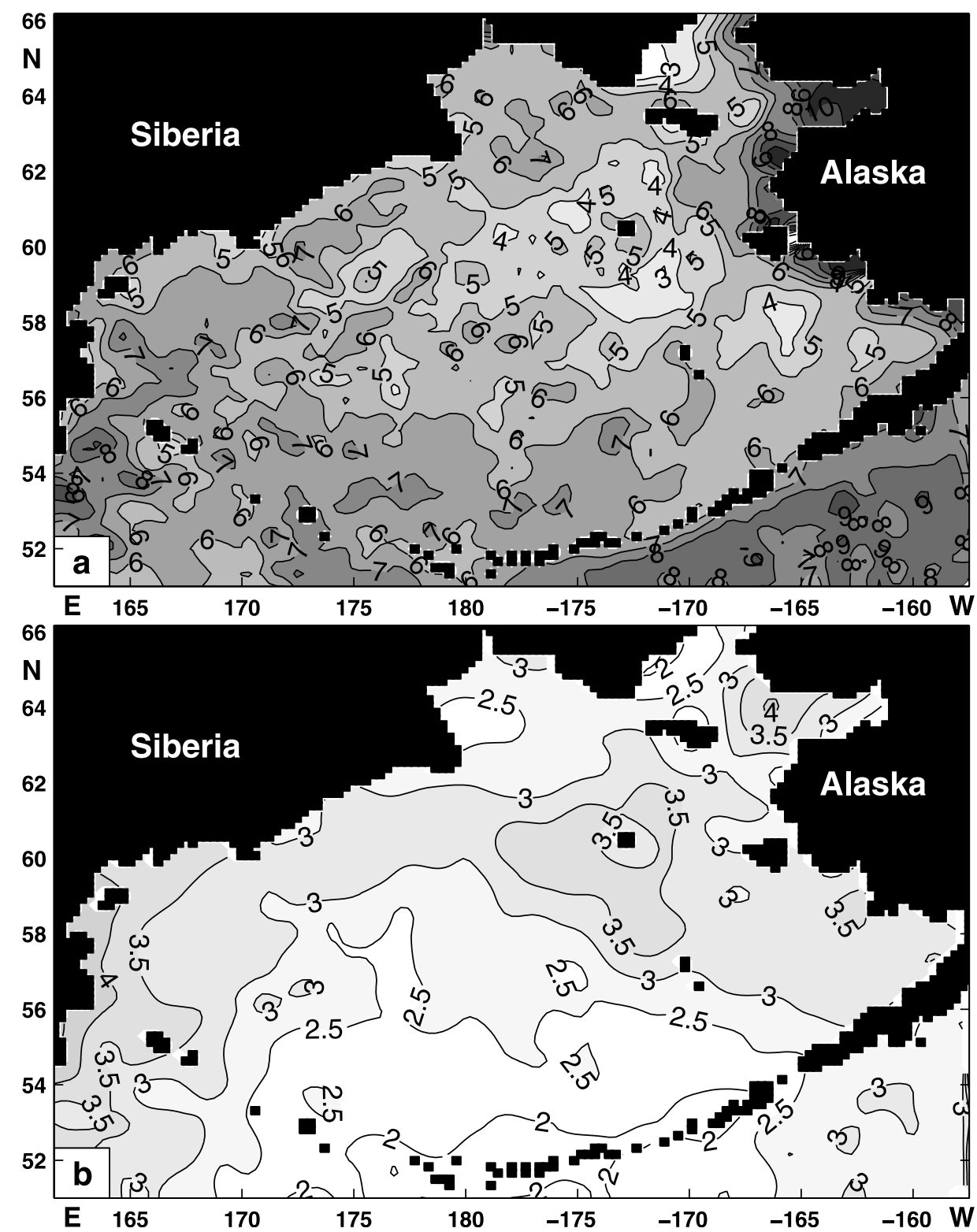

Figure 2. (a) Preprocessed temperature data at $0 \mathrm{~m}$ used in assimilation and (b) the associated standard deviations at $0 \mathrm{~m}$. Contour are in ${ }^{\circ} \mathrm{C}$.

using the standard Lagrangian multiplier technique [e.g., Le Dimet and Talagrand, 1986] by adjusting the errors in the fields that directly control the model solution. These error fields $e_{F}$ included differences between atmospheric forcing fields $F$ and their available estimates $F^{*}$, as well as similar differences between the initial/open boundary conditions for temperature, salinity, horizontal velocity $\mathbf{v}=\{u, v\}$ and sea surface height $\zeta$. The total number of the grid points occupied by the control fields (the dimension of the control vector $c$ ) was $N=856,054$. In addition, the cost function included smoothness constraints, which penalized grid-scale components of the model fields, and the "steady state constraint," which enforced quasi-stationary state by penalizing the difference between the model fields at the beginning and at the end of integration.
[22] The cost function has the form

$$
\begin{aligned}
J= & \frac{1}{P} \sum_{p} \frac{\left(Y_{p}-Y_{p}^{*}\right)^{2}}{\left(\sigma_{Y}^{p}\right)^{2}}+\int_{\Omega} W^{t}[Y(0)-Y(T)]^{2} \frac{d \Omega}{\Omega} \\
& +\int_{\Omega} W_{Y}^{s}(\Delta Y)^{2} \frac{d \Omega}{\Omega}+\int_{S}\left(W^{F}\left(e_{F}\right)^{2}+W_{s}^{F}\left(\Delta e_{F}\right)^{2}\right) \frac{d S}{S}
\end{aligned}
$$

Here $Y=\{T, S, \mathbf{v}, \zeta\}$ denotes the set of prognostic model fields and corresponding data, $F$ stands for the set of surface forcing fields, $\Delta$ is the Laplacian operator, $\Omega$ is the $3 \mathrm{D}$ model domain, $S$ is its upper boundary at $z=0$, and the overbar denotes time average over the period of integration. Summation in the first term is made over the $P=403,156$ observation points described in section 2.1. The index $p$ 

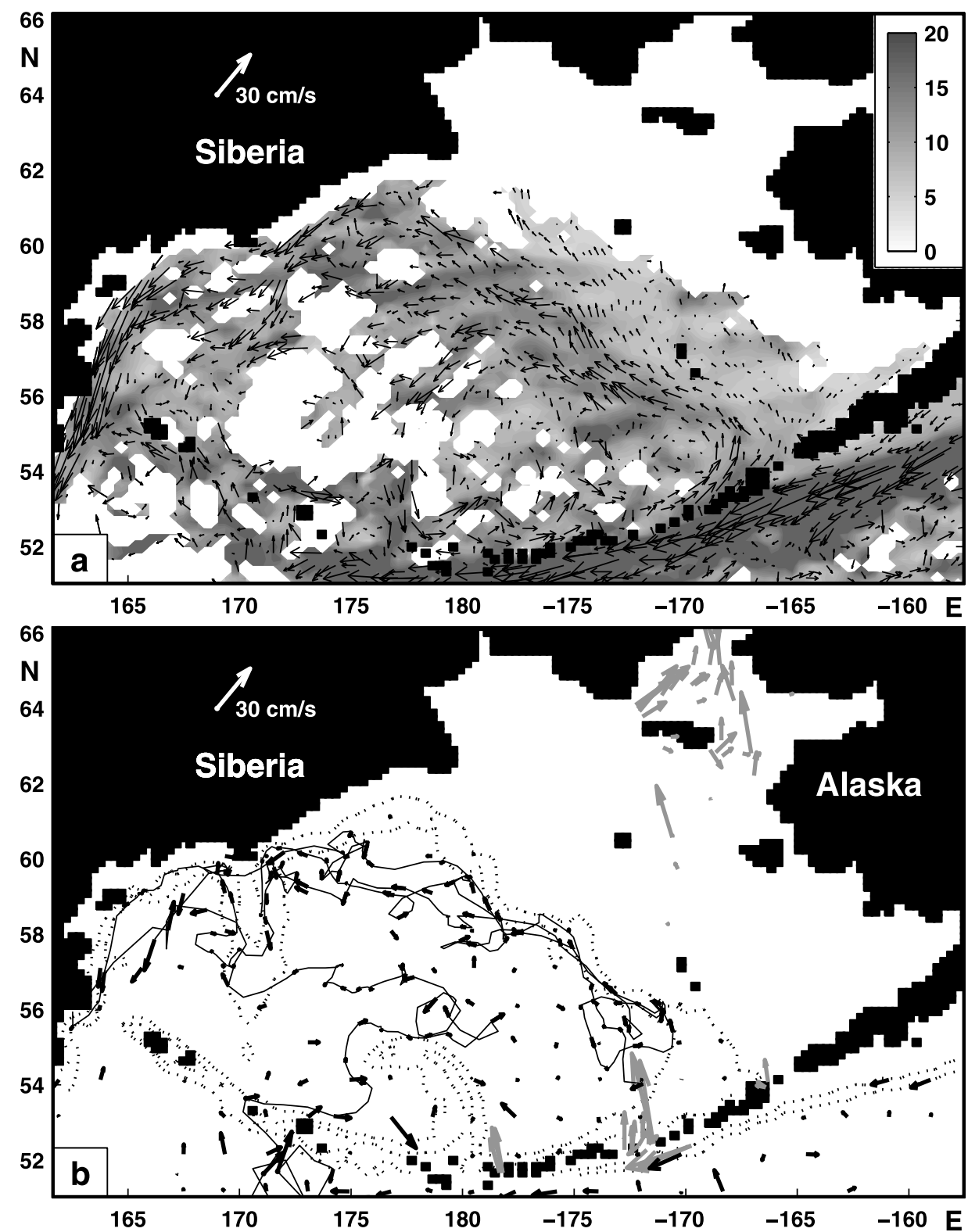

Figure 3. (a) The multiyear mean surface drifter velocities averaged over the model grid cells. The gray scale shows the RMS variance (in $\mathrm{cm} / \mathrm{s}$ ) of the drifter velocity in each grid cell. (b) Long-term mooring velocities (gray arrows) in the upper $200 \mathrm{~m}$ used in assimilation and averaged velocities of Argo drifters at $1000 \mathrm{~m}$ (not used in assimilation). Several typical trajectories of the Argo drifters are shown.

enumerates spatial locations of the observations $Y^{*}$ and the components of $Y$ observed at these locations.

[23] Weighting functions $W$ before the squared quantities have the sense of the inverse error variances, so that the cost function can be interpreted as an argument of the multivariate Gaussian probability distribution [Thacker, 1989]. Under such interpretation the optimal solution is the most probable model state for a given set of observations over a specific time period and their prior error statistics.

\subsection{Error Estimation}

[24] Since the cost function (1) implicitly depends on the set of the adjusted parameters $c$ (control variables), a pos- teriori error covariance can in principle be obtained as the inverse of the Hessian matrix $\mathrm{H}=\partial^{2} J / \partial c^{2}$ [Thacker, 1989].

[25] In practice, inversion of the $N \times N$ Hessian matrix is computationally prohibitive, so we employed an approximate approach assuming that the structure of the SSH error fields roughly followed their patterns of natural variability. These patterns were estimated as the leading empirical orthogonal functions (EOFs) of the covariance matrix C derived from the Aviso SSH anomalies. The corresponding spectrum shows that $90 \%$ of the SSH variability (and error variance) could be explained by $n=20$ modes (Figure 4). The Hessian matrix was inverted in the $n$-dimensional 


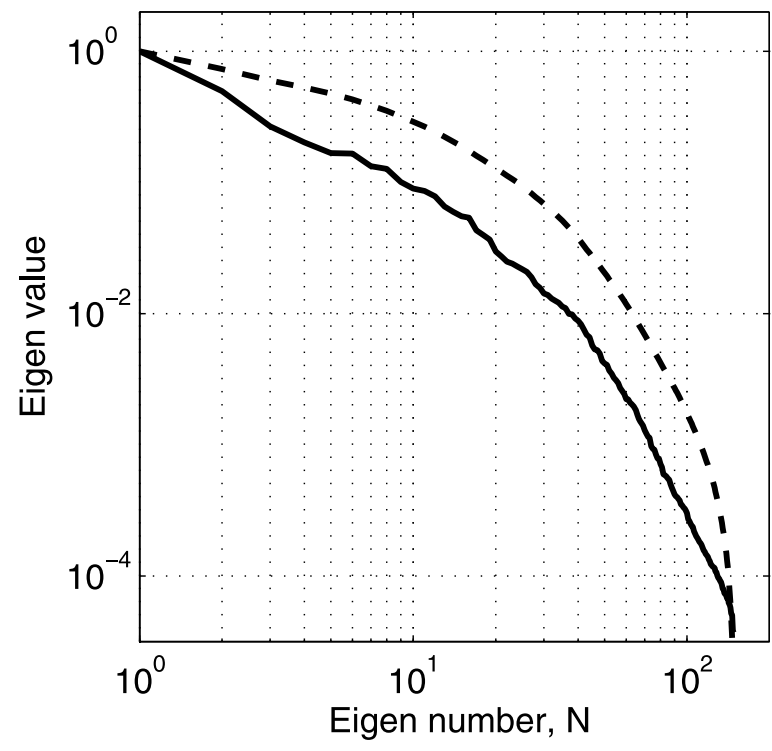

Figure 4. Normalized spectrum of the SSH covariance matrix (solid curve) derived from the Aviso SSH anomalies regridded on the model domain. The dashed curve shows percentage of the SSH variance unexplained by the given number of modes $n$.

subspace spanned by these leading modes and then projected back on the model grid using the relationship

$$
\mathrm{C}_{\zeta}=\mathrm{P}\left(\mathrm{P}^{T} \mathrm{HP}\right)^{-1} \mathrm{P}^{T} .
$$

Here $P$ is the $20 \times 8,722$ matrix whose columns are the 20 eigenvectors of $\mathrm{C}$ with the largest eigenvalues, 8,722 is the number of SSH model field grid points, and $T$ denotes transposition. Mapping the square root of the diagonal elements of $\mathrm{C}_{\zeta}$ gives an estimate of the uncertainty of the optimized MDT (see section 3.1).

[26] The error covariance of the surface geostrophic velocities is estimated using the relationship

$$
\mathrm{C}_{\mathbf{v}}=\mathrm{G}_{\mathbf{v}}^{T} \mathrm{C}_{\zeta} \mathrm{G}_{\mathbf{v}}
$$

where

$$
\mathbf{G}_{\mathbf{v}}=\frac{g \rho_{0}}{f}\left[\frac{\partial}{\partial y} ;-\frac{\partial}{\partial x}\right]
$$

is the matrix composed of the finite difference representations of the operators $\partial_{y}$ and $-\partial_{x}$. Here $g$ is the gravity acceleration, $\rho_{0}=1.025 \mathrm{~g} / \mathrm{cm}^{3}$ is the mean density of seawater and $f$ is the Coriolis parameter. The spatial distribution of the velocity error variance is obtained by taking the square root of the diagonal elements of $\mathrm{C}_{\mathbf{v}}$.

[27] Seasonality of the T/S observations may result in biasing the MDT toward summer conditions. To estimate this effect we calculated separately the baroclinic impacts of the winter and summer T/S distributions on the MDT. It was found that the mean RMS difference between such "seasonal" MDT estimates is about $3 \mathrm{~cm}$. The respective MDT distributions show differences at small spatial scales in the major part of the domain. The only exception is the Alaskan shelf in the east where the difference between the summer and winter MDTs is the most profound. Overall, we estimate that seasonality in the T/S data may result in a bias of $1-2 \mathrm{~cm}$ over the major part of the basin with an increase to $2-3 \mathrm{~cm}$ on the Alaskan shelf.

\section{MDT of the Bering Sea}

\subsection{General Features}

[28] Since the optimized surface velocities below the Ekman layer are in approximate geostrophic balance with the MDT (optimized SSH field), the reconstructed MDT contours (Figure 5a) are conveniently interpreted as streamlines of the mean geostrophic currents at the surface. The circulation pattern reveals the following major structures: (1) an intense (30-40 cm/s) Alaskan Stream south of the Alaska Peninsula, (2) a somewhat weaker $(10-20 \mathrm{~cm} / \mathrm{s})$ Aleutian North Slope Current embracing the southern and northern flanks of the Aleutian Arc, (3) the $30-40 \mathrm{~cm} / \mathrm{s}$ strong Kamchatka Current on the west, and (4) a relatively weak $(5-15 \mathrm{~cm} / \mathrm{s})$ cyclonic circulation occupying the deep part of the Bering Sea. According to Figure 5a, a significant portion of this cyclonic gyre originates in the Near Strait with the rest coming from the inflow through other Aleutian passages.

[29] The circulation shown in Figure 5a is in good qualitative agreement with the results of Stabeno et al. [2005] who describe gradual leakage of the Alaskan Stream though the passages in the Aleutian Arc. In their earlier work, Stabeno and Reed [1994] estimated the splitting point of the Bering Slope Current, which occupies the eastern flank of the deep cyclonic gyre. According to their analysis of surface drifters, the current splits into two branches around $60^{\circ} \mathrm{N}, 176^{\circ} \mathrm{E}$ : at this point a larger part of the surface flow begins to form the Kamchatka Current, while the rest takes the path to the Arctic Ocean. In Figure 5a this splitting occurs at $61^{\circ} \mathrm{N} 178^{\circ} \mathrm{W}$, an insignificant difference given the 2-3 cm uncertainty of our result in this area (Figure 6).

[30] The pattern in Figure 5a does not reveal a clear split of the Kamchatka Current into coastal and offshore branches in the vicinity of the Shirshov Ridge as was shown by Panteleev et al. [2006b]. Instead, a relatively broad westward current across the Kamchatka Basin has been obtained. This difference can be attributed to the seasonal nature of the "offshore branch" of the Kamchatka Current.

[31] The mean mismatch between the reconstructed surface velocities and assimilated drifter velocities (Figure 3a) is $8.2 \mathrm{~cm} / \mathrm{s}$. It is unlikely that better agreement could be obtained between the climatological velocity with mean amplitude of approximately $10 \mathrm{~cm} / \mathrm{s}$ and the highly variable surface currents derived from the drifter trajectories affected by eddies and small-scale variations of the wind stress. Similar discrepancies (on the order of 7-9 $\mathrm{cm} / \mathrm{s}$ ) were observed by Maximenko et al. [2009] who estimated velocity errors in three global MDT products and by Panteleev et al. [2006b] who also obtained similarly high model-surface drifter velocity misfits. Despite this, the optimized surface velocities in the core of the Kamchatka Current are about $22 \mathrm{~cm} / \mathrm{s}$, in relatively good agreement with local drifter velocities $(20-30 \mathrm{~cm} / \mathrm{s})$ [see Hughes et al., 1974] (also see Figure 3a). Similar agreement was obtained for the Alaskan Stream. For example, Stabeno et al. [2005] observed a 

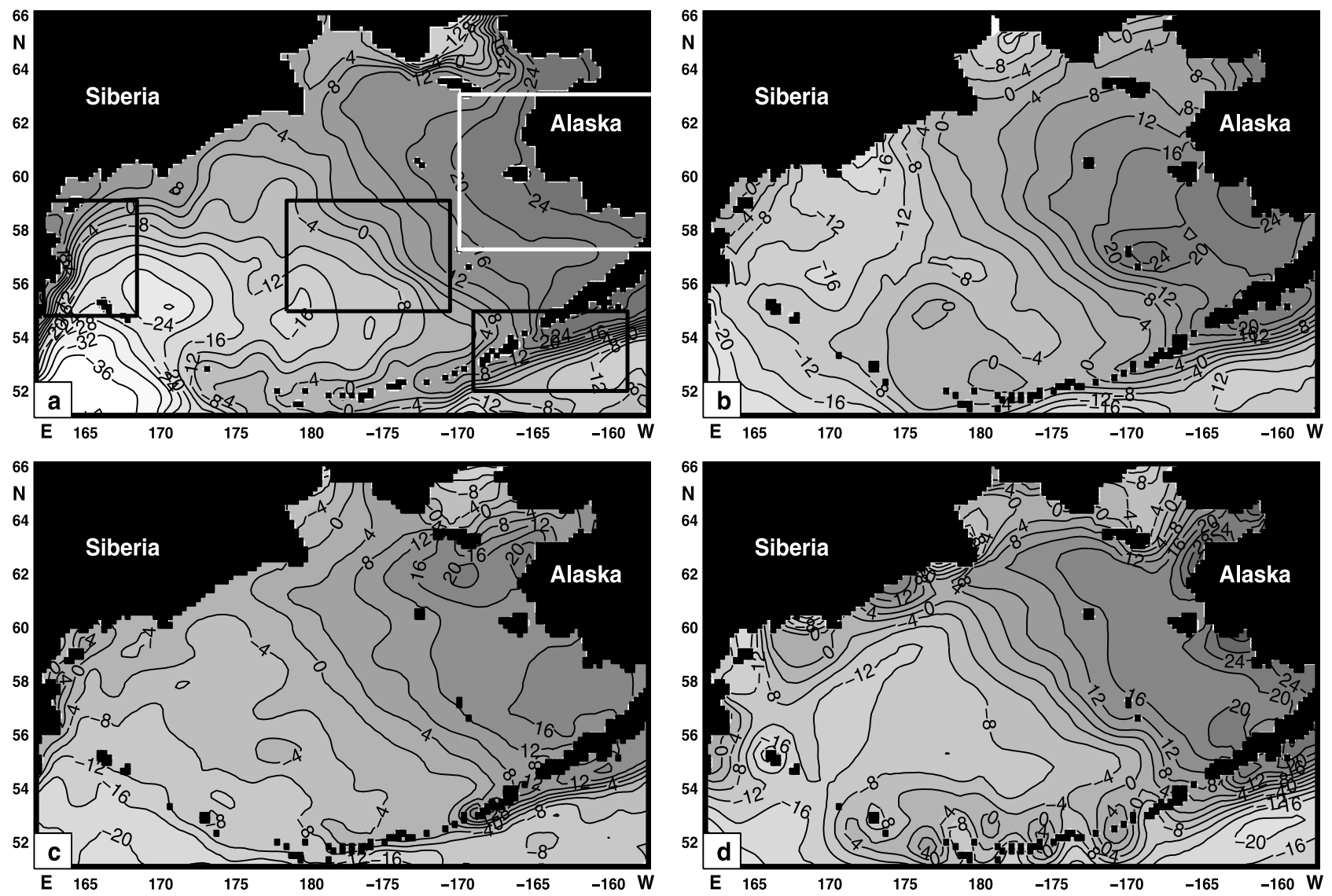

Figure 5. The mean dynamic topographies of the Bering Sea obtained (a) in the present study, (b) by Rio et al. [2005], (c) by Rio et al. [2009], and (d) by merging the EGM08 geoid model with altimeter data. Validation subdomains for the presented MDT are shown by solid black rectangles for drifter intercomparison experiments and by white rectangle for 4DVar intercomparison experiment. Contour interval is $4 \mathrm{~cm}$.

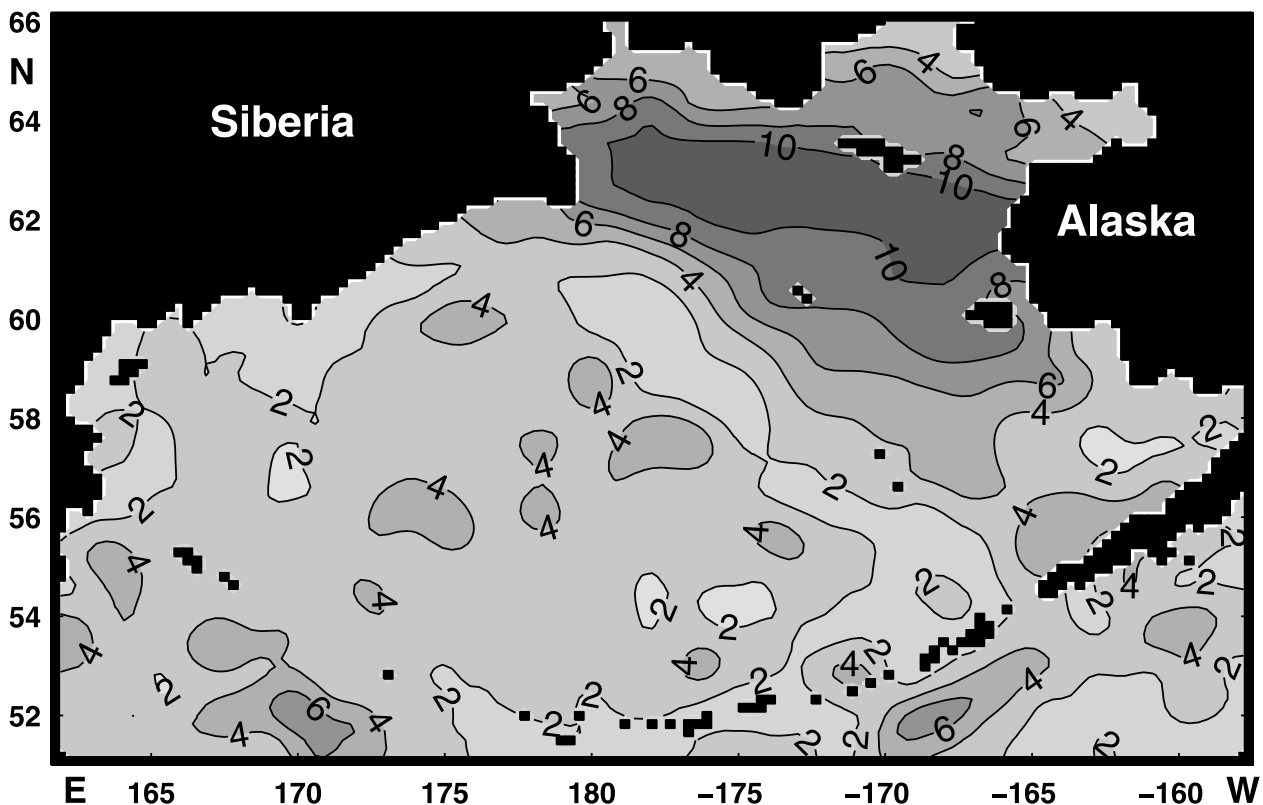

Figure 6. A posteriori RMS error variance map for the MDT. Contour interval is $2 \mathrm{~cm}$. 
4 year mean velocity of $40 \mathrm{~cm} / \mathrm{s}$ at $100 \mathrm{~m}$ near the Amukta Pass, which is close to our optimized estimate of $30 \mathrm{~cm} / \mathrm{s}$.

[32] To further validate the MDT, we compared the optimized velocity field at $1000 \mathrm{~m}$ with independent velocity data derived from the Argo floats. At this depth the average velocity of the floats is $4.6 \mathrm{~cm} / \mathrm{s}$, which is close to the mean optimized velocity magnitude of $3.7 \mathrm{~cm} / \mathrm{s}$. We consider this to be in good agreement with observations because a significant fraction of Argo drifters are involved in mesoscale motions resulting in a higher mean Lagrangian velocity compared to the mean Eulerian velocity. Interestingly, the optimized velocities in the Kamchatka Current $(10 \mathrm{~cm} / \mathrm{s})$ and the Alaskan Stream $(8 \mathrm{~cm} / \mathrm{s})$ at $1000 \mathrm{~m}$ agree almost perfectly with the estimates of $11 \mathrm{~cm} / \mathrm{s}$ and $8 \mathrm{~cm} / \mathrm{s}$ derived from Argo drifters (Figure 3b).

[33] In the major Aleutian Passes the volume transports driven by the MDT shown in Figure 5a were found to be 2.5-7 times larger than the those obtained by Stabeno et al. [1999] by the dynamical method. This discrepancy is likely due to underestimation of the barotropic velocity in the Aleutian straits by the dynamical method. Recent observations by Stabeno et al. [2005] seem to support this suggestion, as they revealed substantial (up to $50 \mathrm{~cm} / \mathrm{s}$ ) northward currents at 100-200 m, indicating similarity with our result and the barotropic nature of the flow through the Aleutian passes.

[34] Inspection of the error map in Figure 6 shows that the MDT errors are significantly smaller $(2-3 \mathrm{~cm})$ than the typical error estimates of 6-8 $\mathrm{cm}$ obtained for the global products [e.g., Maximenko et al., 2009]. Such improvement can be explained by the extensive database and stronger dynamical constraints underlying the new MDT. The pronounced maximum in the error field between $62^{\circ}$ and $64^{\circ} \mathrm{N}$ (Figure 6) is caused by ice cover obstructing observations in winter. A certain decrease of the uncertainty north of St. Lawrence Island is due to the relatively dense mooring observations in that area (cf. Figure 3b). The respective velocity error variances, computed using (3)-(4), range from $2-4 \mathrm{~cm} / \mathrm{s}$ indicating robustness of the flow pattern shown in Figure 5a.

[35] It is necessary to note that our approach does not take into account residual tidal velocities, which do not exceed $0.2-0.5 \mathrm{~cm} / \mathrm{s}$ in the open sea, but can be as large as $2-3 \mathrm{~cm} / \mathrm{s}$ along the continental slope and reach $5-10 \mathrm{~cm} / \mathrm{s}$ around the islands of the Aleutian Arc [Kowalik, 1999]. At the same time, the residual tidal velocities are known to create trapped clockwise circulations around the islands, thus minimizing their effect on the total volume transport in the open Bering Sea.

[36] Overall, the obtained MDT and associated currents are in good agreement with the previous studies and allow reasonable quantitative assessment of the mean background circulation in the Bering Sea. Importantly, the SSH pattern shown in Figure 5a is dynamically balanced with the climatological temperature and salinity fields in the region. In section 3.2 we validate the product against MDTs obtained by alternative methods.

\subsection{Validation Against Other Products}

\subsubsection{MDTs of the Bering Sea}

[37] An unprecedented increase in the amount of data on surface winds, currents, and SSH anomalies has fueled numerous efforts to obtain accurate MDT estimates from observations constrained by simplified dynamics. Niiler et al. [2003] employed surface drifter velocities, wind stress, and $\mathrm{SSH}$ anomalies to produce the first global MDT at $0.5^{\circ}$ resolution. In a more comprehensive effort, Rio et al. [2005, hereinafter R05] combined these data with temperature and salinity from the World Ocean Atlas [Conkright et al., 2002] to produce a more accurate estimate. Most recent efforts by Maximenko et al. [2009] and Rio et al. [2009, hereinafter R09] employ diverse in situ and remotely sensed observations in conjunction with the GGM02C gravity model [Riegber et al., 2005]. A good MDT estimate based on the Earth Gravitational Model 2008 (EGM08) geoid and altimeter data only was obtained recently by Andersen and Knudsen [2009, hereinafter A09] (see also http:// gracetellus.jpl.nasa.gov/data/dot/).

[38] All these efforts were made on the global scale with resolutions $0.5^{\circ}$ or higher. Additional difficulties in retrieving the MDT from observations do arise in subpolar regions, where drifters and altimetry are obscured by ice and the dominant scales get smaller due to a decreasing deformation radius.

[39] Figure 5 gives a comparison of our product with three latest MDTs: two developed by Rio and others in the Aviso altimetry processing center (Figures $5 \mathrm{~b}$ and $5 \mathrm{c}$ ) and the third one by the Danish Space Center and the Jet Propulsion Laboratory (Figure 5d). All four patterns have much in common: the Alaskan Stream south of Alaska Peninsula, northeasterly Slope Current in the center, and the Kamchatka Current on the east. Figures $5 \mathrm{~b}-5 \mathrm{~d}$ also demonstrate a basin-scale SSH difference of 40-50 cm between the Alaska and the southwestern corner of the domain, which is $15 \mathrm{~cm}$ less than in Figure 5a. There are, however, much larger quantitative differences between the patterns. First, the Kamchatka Current is barely visible in Figure 5c, and especially in Figures 5b and 5d where SSH contours have the correct offshore slope only along limited portions of the coastline. R09 is more realistic, but they still underestimate the current's width and velocity. Second, MDTs in Figures $5 \mathrm{~b}-5 \mathrm{~d}$ drop $12-18 \mathrm{~cm}$ between St. Lawrence island and the Bering Strait, correctly indicating that the Bering Strait transport is driven by the $\mathrm{SSH}$ difference between the Pacific and the Arctic oceans, but the flow through the strait appears to be completely ageostrophic. In contrast, the presented MDT finds a $25 \mathrm{~cm}$ difference between St. Lawrence Island and the Chukchi Peninsula and the mean flow through the Bering Strait is geostrophically balanced. This agrees well with the results of Cherniawsky et al. [2005], who found that the Bering Strait transport can be retrieved from sea level anomalies with reasonable accuracy using geostrophy. Finally, the cyclonic gyre in the deeper southwestern part of the Bering Sea is not clearly visible in the R05 and R09 MDT maps. Existence of this gyre is supported by drifter data (Figure 3a) [Stabeno et al., 1999; Johnson et al., 2004], data-constrained model simulations [Yaremchuk, 2001; Wunsch et al., 2009]; and the A09 MDT (Figure 5d) which is presumably more accurate in the open sea. The A09 pattern also appears to be more consistent with the Argo float data (Figure 3b) and the result of Stabeno and Reed [1994] as it shows a clear meridional inflow into the domain at $167^{\circ}-170^{\circ} \mathrm{E}$. 
Table 1. Difference $(\mathrm{cm} / \mathrm{s})$ Between the Geostrophic Currents Obtained With Various MDT Products and Drifter Velocity Data Used in the Present Study ${ }^{\mathrm{a}}$

\begin{tabular}{lcccc}
\hline Region & R05 & A09 & R09 & 4DVar \\
\hline KC & 12.0 & 13.2 & 11.0 & 9.7 \\
BSC & 10.1 & 9.5 & 9.6 & 9.1 \\
AS & 17.6 & 17.3 & 18.0 & 15.4 \\
Mean & 13.2 & 13.3 & 12.8 & 11.4 \\
\hline
\end{tabular}

${ }^{\mathrm{a}}$ Most of the drifters were drogued at $40 \mathrm{~m}$.

[40] Qualitative comparison of Figures 5a-5d emphasizes the validity of additional in situ data in reconstructing the MDT in nearshore regions, where altimetry and gravity observations tend to be less accurate (cf. Figure $5 \mathrm{~d}$ and Figures $5 \mathrm{a}-5 \mathrm{c}$ near the Aleutian arc). On the other hand, the EGM08 geoid appears to be more accurate in the center of the Sea, as it is able to reproduce the cyclonic gyre over the deep part of the basin and the above mentioned meridional inflow around $170^{\circ} \mathrm{E}$.

\subsubsection{Quantitative Validation}

[41] To assess the MDT products quantitatively, we used the Aviso methodology: three domains well covered by drifters were picked, gridded Aviso SSH anomalies from http://www.aviso.oceanobs.com were added to each MDT, and the resulting geostrophic currents were compared with the currents deduced from drifter trajectories. The test domains (Figure 5a) cover the major circulation features of the Bering Sea and include the Kamchatka Current (KC), the Bering Slope Current (BSC), and the Alaskan Stream (AS). Table 1 summarizes the calculated RMS velocity discrepancies.

[42] The presented 4DVar MDT demonstrates smaller errors, especially in the $\mathrm{KC}$ region, where all the alternative MDTs fail to reproduce a continuous current with realistic velocities. This success may be partially due to the fact that the mean drifter velocities (Figure 3a) were assimilated in the 4DVar MDT. Note that both the R05 and the R09 products were also developed by taking the drifter information into account. Table 1 also shows gradual improve- ment of the MDT products with time: there is an overall decrease of the mean error from left to right indicating a tendency of convergence to the "true MDT." It is also noteworthy that A09 outperforms R09 in the BSC and AS regions; although it was compiled with altimetry data only, it utilized a better geoid.

[43] In addition, we validated the performance of the above MDTs in approximating the nearshore geostrophic currents in Kuskokwim Bay, where 32 drifters were launched by Quinhagak fishermen in July-October 2008.

[44] Using the 4DVar algorithm described in section 2, drifter velocities were assimilated together with climatological $\mathrm{T} / \mathrm{S}$ distributions into the model configured in the $4^{\circ} \times 4^{\circ}$ domain shown in Figure 7 . The optimized SSH field was averaged over the assimilation period and used as a benchmark for assessing the quality of the MDTs. This assessment was done by comparing the above mentioned time-averaged distribution $\zeta_{b}$ (Figure 7a) with the sum $\zeta_{s}$ of MDT and Aviso anomalies averaged over the period of the Kuskokwim experiment.

[45] To quantify the assessment, we also computed relative errors

$$
\xi=\sqrt{\left\langle\left(\zeta_{s}-\zeta_{b}\right)^{2}\right\rangle /\left\langle\left(\zeta_{b}-\left\langle\zeta_{b}\right\rangle\right)^{2}\right\rangle},
$$

where angular brackets stand for the average over the region with drifter trajectories shown by the white rectangle in Figure $7 \mathrm{a}$. The values of $\xi_{s}$ were found to be $0.79,1.71$, 1.06, and 1.27 for the 4DVar, R05, R09, and A09 MDTs, respectively. These large values are explained by higher MDT errors in shallow regions, errors in Aviso SSH anomalies, and errors in $\zeta_{b}$ itself. Nevertheless, the mean $\mathrm{SSH}$ distribution, defined as the sum of the Aviso anomalies and 4DVar MDT (Figure 7b), is in better agreement $(\xi=$ 0.79) with the benchmark field (Figure 7a) than with the corresponding SSH distributions derived from the R05 (Figure $7 \mathrm{c}, \xi=1.71)$, A09 $(\xi=1.27)$, or R09 $(\xi=1.09)$ MDTs.

[46] All these examples illustrate the significant advantage of the presented MDT as compared to the best global pro-

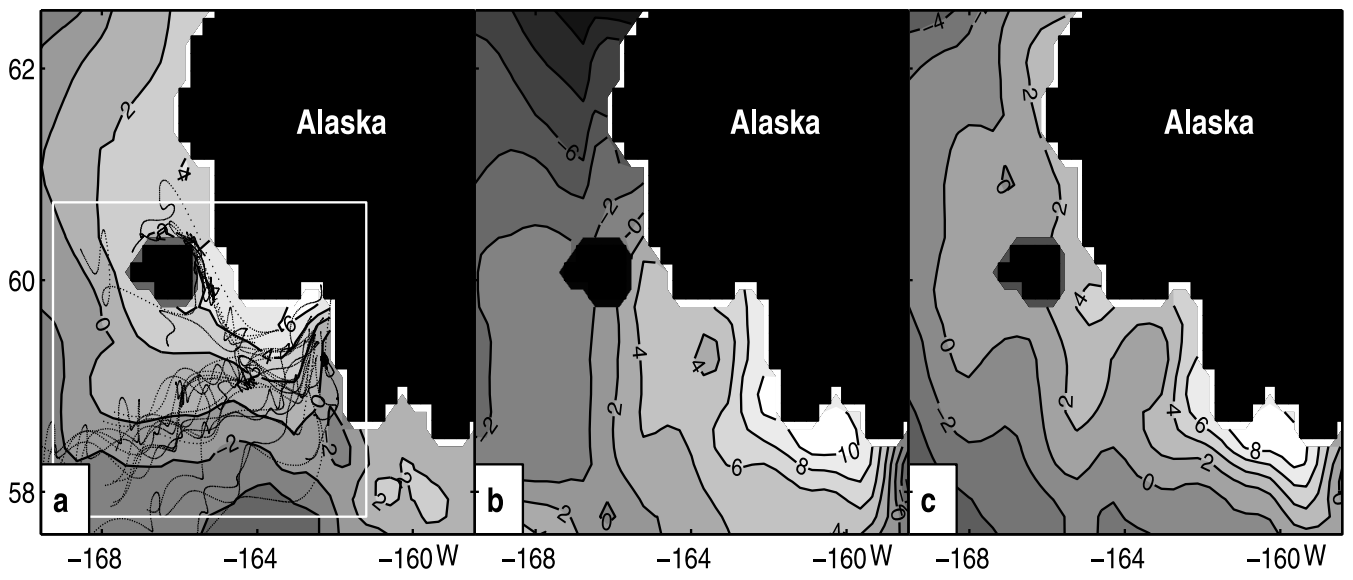

Figure 7. (a) Mean SSH derived from assimilating drifter velocities in the Kuskokwim Bay and the mean SSH obtained by adding the (b) presented MDT and (c) MDT of Rio et al. [2005] to Aviso SSH anomalies averaged over the duration of the Kuskokwim drifter experiment (7 July 2008 to 12 October 2008). 
ducts, which generally suffer from larger errors in nearcoastal regions. Apart from somewhat better resolution, our product benefits from much better usage of the dynamical information which significantly constrains the $\mathrm{SSH}$ field near the coast.

\section{Summary and Discussion}

[47] A quantitative estimate of the MDT in the Bering Sea has been presented. The product is obtained by combining historical oceanographic and atmospheric observations with high-resolution model dynamics in the framework of the variational technique. The optimized circulation is dynamically balanced and statistically consistent with the utilized data.

[48] The presented dynamic topography is validated against the three most recent global MDT products. Two of them (R05 and R09) were derived by merging in situ observations with winds, satellite altimetry, and geoid models. The third product (A09) is based only on altimeter data and the most recent EGM08 geoid. Comparison has shown that the first two MDTs (R05 and R09) perform better than A09 near the land, but are nevertheless noticeably worse than the presented product. On the other hand, A09 does much better job in representing the SSH pattern in the open Bering Sea, indicating a considerable increase in the accuracy of the EGM08 geoid compared to the previous models. Overall, the presented MDT has shown better performance against independent drifter and mooring observations while demonstrating somewhat more realistic geostrophic circulation, especially near the Kamchatka coastline and north of St. Lawrence island.

[49] We conducted a rigorous error analysis of the MDT and related geostrophic currents. The MDT uncertainties were computed by inverting the Hessian matrix of the assimilation problem in the subspace spanned by the gravest modes of SSH variability observed from satellites. Geostrophic velocity errors were calculated by the appropriate transformation of the SSH error covariance matrix. This analysis has shown the remarkable robustness of our MDT estimate, which is characterized by $\mathrm{SSH}$ errors of $2-3 \mathrm{~cm}$, considerably less than typical error variances $(6-8 \mathrm{~cm})$ of the global MDTs.

[50] The corresponding geostrophic velocity errors range within $2-4 \mathrm{~cm} / \mathrm{s}$ making it possible to quantify the major circulation features in the Bering Sea with a reasonable degree of confidence. In particular, the mean surface currents in the AS $(25-40 \mathrm{~cm} / \mathrm{s})$ and $\mathrm{KC}(15-30 \mathrm{~cm} / \mathrm{s})$ are determined with a formal accuracy of $10-15 \%$, and in the Aleutian North Slope Current (10-20 cm/s) with an accuracy of $20-25 \%$.

[51] Our comparisons with similar products also indicate that the A09 MDT estimate derived from the latest GRACE geoid (EGM08) has more in common with the presented sea surface topography than the MDTs based on earlier versions of the geoid, especially in the open sea regions, where altimeter observations tend to be more accurate.

[52] Having a realistic SSH reference is especially important for successful monitoring of the Bering Sea circulation. Currently, the Jason, Envisat, and GFO satellite altimeter missions provide accurate $\mathrm{SSH}$ anomalies across the entire Bering Sea every 10-30 days, but because of the insufficient knowledge of MDT/geoid, use of these data is not straightforward. We believe that the presented MDT will improve the accuracy in estimating the Bering Sea surface circulation and may even be used for calibrating the geoid models in the region.

[53] Recent changes in the Arctic and North Pacific Climate [e.g., Weller, 1998; Overland et al., 1999, 2000] may seem to contradict the validity of the steady state assumption underlying our analysis. This assumption, however, is imposed in the form of a weak constraint (second term in equation (1)) and allows residual trends in the T/S fields. Their magnitudes of $0.15^{\circ} \mathrm{C} / \mathrm{yr}$ appear to be consistent with the existing experimental estimates for the period of 1974 1994 described by Luchin et al. [2002].

[54] The presented MDT can be viewed and downloaded from http://people.iarc.uaf.edu/ gleb/nprb aleutian_passes/ bering_sea_atlas_register.php together with the optimized climatological temperature, salinity, and velocity distributions. These fields were obtained simultaneously with the 4DVar reconstruction of the MDT but error variance distributions have not yet been produced for them. We are currently working on improving error estimates for the MDT and the other fields of this climatological atlas.

[55] The proposed approach is a relatively inexpensive way to use diverse observational data in deriving an MDT for any region. Because the period of model integration is relatively short, the method can also be viewed as an "iterative diagnostic calculation" with updated initial and boundary conditions. We compared the 4DVar MDT in the southeastern part of our domain with the MDT recently proposed for the Gulf of Alaska by Foreman et al. [2008], and found a very good agreement between these products for the AS region. That shows that these two dynamically constrained approaches have much in common. The limiting factor for our approach is model resolution, which should be kept relatively low, while the diagnostic calculation can be formally done at a very fine resolution of $1 \mathrm{~km}$ [Foreman et $a l ., 2008]$. The variational approach allows us, however, to take into account all available data together with their statistics and provides a consistent formalism for estimating a posteriori errors.

[56] Acknowledgments. Panteleev and Nechaev were supported by the North Pacific Research Board 828 and the NSF ARC-0632154 awards. Panteleev was also partially funded by Japan Agency for Marine-Earth Science and Technology, Japan, and by the International Arctic Research Center. This study was also supported by the Office of Naval Research (program element $0602435 \mathrm{~N}$ ). The authors are grateful to Tom Weingartner and Seth Danielson for providing drifter data of the Kuskokwin 2008 experiment

\section{References}

Andersen, O. B., and P. Knudsen (2009), DNSC08 mean sea surface and mean dynamic topography models, J. Geophys. Res., 114, C11001, doi:10.1029/2008JC005179.

Awaji, T., S. Masuda, Y. Ishikawa, N. Sugiura, T. Toyoda, and T. Nakamura (2003), State estimation of the North Pacific Ocean by a four-dimensional variational data assimilation experiment, J. Oceanogr., 59, 931-943.

Bingham, R. J., and K. Haines (2006), Mean dynamic topography: Intercomparisons and errors, Philos. Trans. R. Soc. Ser. A, 364, 903-916.

Brasseur, P. (1991), A variational inverse method for reconstruction of general circulation fields in the northern Bering Sea, J. Geophys. Res., 96, 4891-4907. 
Chelton, D. B., R. A. deSzoeke, M. G. Schlax, K. E. Naggar, and N. Siwertz (1998), Geographical variability of the first-baroclinic Rossby radius of deformation, J. Phys. Oceanogr., 28, 433-460.

Cherniawsky, J. Y., W. R. Crawford, O. Nikitin, and E. Carmack (2005), Bering Strait transports from satellite altimetry, J. Mar. Res., 63(5), 887-900.

Conkright, M. E., R. A. Locarnini, H. E. Garcia, D. O’Brien, T. P. Boyer, C. Stephens, and J. I. Antonov (2002), World Ocean Atlas 2001: Objective Analyses, Data Statistics, and Figures [CD-ROM documentation], Natl. Oceanogr. Data Cent. Int. Rep. 17, 17 pp., NOAA, Silver Spring, Md

Foreman, M. G. G., W. R. Crawford, J. Y. Cherniawsky, and J. Galbraith (2008), Dynamic ocean topography for the northeast Pacific and its continental margins, Geophys. Res. Lett., 35, L22606, doi:10.1029/ 2008GL035152.

Grotov, A. S., D. Nechaev, G. Panteleev, and M. Yaremchuk (1998), Large scale circulation in the Bellingshausen and Amundsen seas as a variational inverse of climatological data, J. Geophys. Res., 103, 13,011-13,022.

Hoteit, I., B. Cornuelle, and P. Heimbach (2010), An eddy-permitting, dynamically consistent adjoint-based assimilation system for the Tropical Pacific: Hindcast experiments in 2000, J. Geophys. Res., 115, C03001, doi:10.1029/2009JC005437.

Hughes, F. W., L. K. Coachman, and K. Aagaard (1974), Circulation, transport and water exchange in the western Bering Sea, in Oceanography of the Bering Sea With Emphasis on Renewable Resources, edited by D. W. Hood and E. J. Kelley, pp. 59-98, Inst. of Mar. Sci., Univ. of Alaska, Fairbanks, Alaska.

Johnson, G. C., P. J. Stabeno, and S. C. Riser (2004), The Bering Slope Current revisited, J. Phys. Oceanogr., 34, 384-398.

Kowalik, Z. (1999), Bering Sea tides, in Dynamics of the Bering Sea, edited by T. R. Loughlin and K. Ohtani, pp. 92-128, Alaska Sea Grant Coll Program, Fairbanks, Alaska.

Ladd, C., and N. Bond (2002), Evaluation of the NCEP/NCAR reanalysis in the NE Pacific and at the Bering Sea, J. Geophys. Res., 107(C10), 3158, doi:10.1029/2001JC001157.

Le Dimet, F. X., and O. Talagrand (1986), Variational algorithms for analysis and assimilation of meteorological observations: Theoretical aspects, Tellus Ser. A, 38, 97-100.

Luchin, V. A., I. P. Semiletov, and G. E. Weller (2002), Changes in the Bering Sea region: Atmosphere-ice-water system in the second half of the twentieth century, Prog. Oceanogr., 55(1-2), 23-44.

Madec, G., P. Delecluse, M. Imbard, and C. Levy (1999), OPA 8.1 ocean general circulation model reference manual, Note Pole Model. 11, 91 pp., Inst. Pierre-Simon Laplace, Paris.

Maximenko, N., P. Niiler, M.-H. Rio, O. Melnichenko, L. Centurioni, D. Chambers, V. Zlotnicki, and B. Galperin (2009), Mean dynamic topography of the ocean derived from satellite and drifting buoy data by three different techniques, J. Atmos. Oceanic Technol., 26(9), 1910-1919.

Mazloff, M., P. Heimbach, and C. Wunsch (2010), An eddy-permitting Southern Ocean state estimate, J. Phys. Oceanogr., 40, 880-899.

Menemelis, D., H. Zhang, P. Heimbach, C. Hill, J. M. Campin, G. Forget, M. Losch, and M. Schodlok (2009), Global ocean and sea ice estimation in the presence of eddies, paper presented at OceanObs'09 Conference, Eur. Space Agency, Venice, Italy.

Nechaev, D., G. Panteleev, and M. Yaremchuk (2005), Reconstruction of the circulation in the limited region with open boundaries: Circulation in the Tsushima Strait, Oceanology, 45(6), 805-828.

Niiler, P. P. (2001), The world ocean surface circulation, in Ocean Circulation and Climate, edited by G. Siedler, J. Church, and J. Gould, pp. 193-204, Academic, San Diego, Calif

Niiler, P., N. Maximenko, and J. McWilliams (2003), Dynamically balanced absolute sea level of the global ocean from near-surface velocity observations, Geophys. Res. Lett., 30(22), 2164, doi:10.1029/ 2003GL018628.

Overland, J. E., J. M. Adams, and N. A. Bond (1999), Decadal variability of the Aleutian low and its relation to high-latitude circulation, J. Clim., $12,1542-1548$.

Overland, J. E., J. M. Adams, and H. J. Mofjeld (2000), Chaos in the North Pacific: Spatial modes an temporal irregularity, Prog. Oceanogr., 47, 337-354.

Panteleev, G., D. Nechaev, and M. Ikeda (2006a), Reconstruction of summer Barents Sea circulation from climatological data, Atmos. Ocean, 44(2), 111-132.

Panteleev, G., P. Stabeno, V. A. Luchin, D. Nechaev, and M. Ikeda (2006b), Summer transport estimates of the Kamchatka Current derived as a variational inverse of hydrophysical and surface drifter data, Geophys. Res. Lett., 33, L09609, doi:10.1029/2005GL024974.
Panteleev, G. G., A. Proshutinsky, M. Kulakov, D. A. Nechaev, and W. Maslowski (2007), Investigation of summer Kara Sea circulation employing a variational data assimilation technique, J. Geophys. Res., 112, C04S15, doi:10.1029/2006JC003728

Panteleev, G., D. A. Nechaev, A. Proshutinsky, R. Woodgate, and J. Zhang (2010), Reconstruction and analysis of the Chukchi Sea circulation in 1990-1991, J. Geophys. Res., 115, C08023, doi:10.1029/2009JC005453.

Powell, B., H. G. Arango, A. M. Moore, E. Di Lorenzo, R. F. Milliff, and D. Foley (2008), 4DVAR data assimilation in the intra-Americas Sea with the Regional Ocean Modeling System (ROMS), Ocean Modell., 23(3-4), 130-145.

Riegber, C., R. Schmidt, F. Fletcher, R. König, U. Meyer, K.-H. Neumayer, P. Schwintzer, and S. Y. Zhu (2005), An Earth gravity field model complete to degree and order 150 from GRACE: EIGEN-GRACE02S, J. Geodyn., 39, 1-10.

Rio, M.-H., P. Schaeffer, J.-M. Lemoine, and F. Hernandez (2005), Estimation of the ocean mean dynamic topography through the combination of altimetric data, in-situ measurements and GRACE geoid: From global to regional studies, paper presented at GOCINA International Workshop, Luxembourg.

Rio, M-H., P. Schaeffer, G. Moreaux, S. Bourgogne, J-M. Lemoine, and E. Bronner (2009), A new mean dynamic topography computed over the global ocean from GRACE data altimetry and in-situ measurements, paper presented at OceanObs09 Conference, Eur. Space Agency, Venice, Italy.

Stabeno, P. J., and R. K. Reed (1994), Circulation in the Bering Sea basin observed by satellite-tracked drifters: 1986-1993, J. Phys. Oceanogr. 24, 848-854.

Stabeno, P. J, J. D. Schumacher, and K. Ohtani (1999), The physical oceanography of the Bering Sea, in Dynamics of the Bering Sea, edited by T. R. Loughlin and K. Ohtani, pp. 1-28, Alaska Sea Grant Coll. Program, Fairbanks, Alaska.

Stabeno, P. J., D. G. Kachel, and M. E. Sullivan (2005), Observation from moorings in the Aleutian passes: Temperature, salinity and transport, Fish. Oceanogr., 14, suppl. 1, 39-54.

Stammer, D., C. Wunsch, R. Giering, C. Eckert, P. Heimbach, J. Marotzke, A. Adcroft, C. N. Hill, and J. Marshall (2002), Global circulation during 1992-1997, estimated from ocean observations and a general circulation model, J. Geophys. Res., 107(C9), 3118, doi:10.1029/2001JC000888.

Thacker, W. C. (1989), On the role of Hessian matrix in fitting models to measurements, J. Geophys. Res., 94, 6177-6196.

Tziperman, E., and W. C. Thacker (1989), An optimal-control/adjoint equation approach to studying the oceanic general circulation, J. Phys. Oceanogr., 19, 1471-1485.

Weller, G. E. (1998), Regional impacts of climate change in the Arctic and Antarctic, Ann. Glaciol., 27, 543-552.

Wilson, S. (2000), Launching the ARGO armada, Oceanus, 42(1), 17-19.

Woodgate, R. A., K. Aagaard, and T. Weingartner (2005), Monthly temperature, salinity, and transport variability of the Bering Strait through flow, Geophys. Res. Lett., 32, L04601, doi:10.1029/2004GL021880.

Wunsch, C. (1996), The Ocean Circulation Inverse Problem, 442 pp., Cambridge Univ. Press, Cambridge, U. K.

Wunsch, C., P. Heimbach, R. Ponte, and I. Fukumori (2009), The global general circulation of the ocean estimated by the ECCO consortium, Oceanography, 22, 88-103.

Yaremchuk, M. (2001), A reconstruction of large scale circulation on the Pacific Ocean north of $10^{\circ} \mathrm{N}, J$. Geophys. Res., 106, 2331-2344.

Yaremchuk, M., D. Nechaev, and G. Panteleev (2009), A method of successive corrections of the control subspace in the reduced-order variational data assimilation, Mon. Weather Rev., 137, 2966-2978.

Yoshinari, H., N. A. Maximenko, and P. W. Hacker (2006), YoMaHa'05: Velocity data assessed from trajectories of Argo floats at parking level and at the sea surface, Tech. Note 4, 20 pp., Int. Pac. Res. Cent., Honolulu.

T. Kikuchi, Research Institute for Global Change, Japan Agency for Marine-Earth Science and Technology, 2-15 Natsushima-cho, Yokosuka, Kanagawa 237-0061, Japan.

V. Luchin, Far Eastern Branch, Russian Academy of Science, 50 Svetlanskaya St., Vladivostok 690950, Russia

D. A. Nechaev, Department of Marine Science, University of Southern Mississippi, 1020 Balch Blvd., Stennis Space Center, MS 39529, USA.

G. Panteleev, International Arctic Research Center, University of Alaska, 930 Koyukuk Dr., P.O. Box 757340, Fairbanks, AK 99775, USA. (gleb@ iarc.uaf.edu)

P. J. Stabeno, NOAA Pacific Marine Environmental Laboratory, 7600 Sand Point Way NE, Seattle, WA 98115, USA.

M. Yaremchuk, Naval Research Laboratory, Code 7321, Bldg. 1009, Stennis Space Center, MS 39529, USA. 